\title{
Effects of a new respiratory muscle training device in community-dwelling elderly men: an open-label, randomized, non-inferiority trial
}

Sang Hun Kim', Myung-Jun Shin², Jang Mi Lee ${ }^{3}$, Sungchul Huh ${ }^{4}$ and Yong Beom Shin²

\begin{abstract}
Background: Respiratory muscle training (RMT) has various clinical benefits in older adults; however, the low adherence to training remains a challenging issue. The present study aimed to confirm the efficacy of a new device that combines inspiratory muscle training and a positive expiratory pressure (IMT/PEP) compared to that of a Threshold IMT device (Philips Respironics Inc), and to determine whether home-based training differed from rehabilitation center training.

Methods: This four-arm, multicenter, parallel, non-inferiority trial randomized 80 active community-dwelling older men (mean age $=72.93 \pm 5.02$ years) to center-based groups (new IMT/PEP device or Threshold IMT device; 16 supervised sessions) or home-based groups (new IMT/PEP device or Threshold IMT device; 2 supervised sessions and individual sessions). Participants in all groups performed RMT twice a day for 8 weeks. Assessments were performed at baseline and post-training. The primary outcomes were maximum inspiratory pressure and maximal expiratory pressure. The secondary outcomes included forced vital capacity and forced expiratory volume in the first second, peak cough flow, diaphragm thickness, $V_{2}$ peak, the International Physical Activity Questionnaire score, electromyographic activities of the sternocleidomastoid muscle, and skeletal muscle mass and phase angle as measured by bioimpedance analysis. In addition, rates of adherence to each protocol were also compared.
\end{abstract}

Results: Among all groups, the maximal inspiratory pressure was improved post-training, while the maximal expiratory pressure showed improvement only in the IMT/PEP groups. The overall non-inferiority of the IMT/PEP device was thus validated. A statistically significant improvement in diaphragm thickness was found. However, no consistent improvement was shown in other secondary outcomes. No significant difference in training adherence rate between protocols was observed (mean adherence rate of 91-99\%).

Conclusion: Compared to the Threshold IMT, the new IMT/PEP device did not result in a significant difference in maximal inspiratory pressure but did improve maximal expiratory pressure in older men. The IMT/PEP device's improved usability, which is associated with exercise adherence, provided distinct advantages in this cohort. If proper education is first provided, home-based RMT alone may provide sufficient effects in older individuals.

Trial registration: This trial was registered in the database cris.nih.go.kr (registration number KCT0003901) on 10/05/2019.

\footnotetext{
*Correspondence: yi0314@gmail.com

${ }^{2}$ Department of Rehabilitation Medicine, Biomedical Research Institute,

Pusan National University Hospital and Pusan National University School

of Medicine, Busan, Republic of Korea

Full list of author information is available at the end of the article
}

(c) The Author(s) 2022. Open Access This article is licensed under a Creative Commons Attribution 4.0 International License, which permits use, sharing, adaptation, distribution and reproduction in any medium or format, as long as you give appropriate credit to the original author(s) and the source, provide a link to the Creative Commons licence, and indicate if changes were made. The images or other third party material in this article are included in the article's Creative Commons licence, unless indicated otherwise in a credit line to the material. If material is not included in the article's Creative Commons licence and your intended use is not permitted by statutory regulation or exceeds the permitted use, you will need to obtain permission directly from the copyright holder. To view a copy of this licence, visit http://creativecommons.org/licenses/by/4.0/. The Creative Commons Public Domain Dedication waiver (http://creativeco mmons.org/publicdomain/zero/1.0/) applies to the data made available in this article, unless otherwise stated in a credit line to the data. 

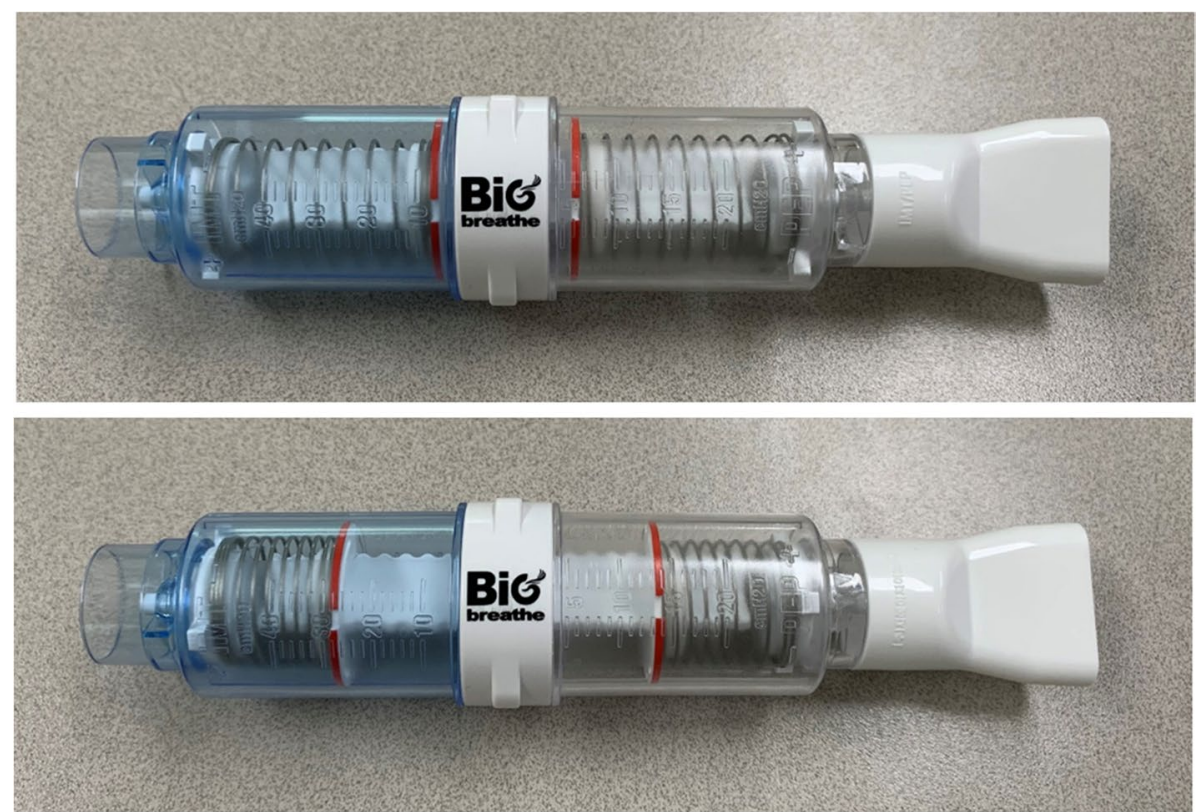

Fig. 1 The new combined IMT/PEP device (numbers presented are in $\mathrm{mm}$ )

Keywords: Breathing exercises, Diaphragm, Exercise therapy, Maximal respiratory pressure, Respiratory function test, Respiratory muscles

\section{Background}

Physiological pulmonary function changes in older individuals are characterized by reduced lung elasticity, respiratory muscle strength, and chest wall compliance $[1$, 2]. Sarcopenia is defined as the age-related loss of skeletal muscle mass, muscle strength, and reduced physical performance [3]. In addition, respiratory muscle strength decreases in older individuals with sarcopenia [4]. These physiological changes in older individuals make it difficult to maintain physical activity, which is essential for maintaining a healthy lifestyle [5].

The weakness of respiratory muscles in older individuals can increase the prevalence of diseases and disability [6]. Therefore, various exercises have been proposed to improve physical performance in older individuals [7, 8]. Several clinical effects of respiratory muscle training (RMT), such as a strengthened diaphragm and improved aerobic capacity and coughing ability, have been reported in older individuals $[9,10]$. RMT has improved physical performance in less-fit individuals, which includes older individuals [11]. However, low adherence to pulmonary rehabilitation exercise, including RMT, remains problematic [12]. For these reasons, we have designed a new device that combines inspiratory muscle training (IMT) and positive-expiratory pressure (PEP) for enhancing exercise adherence and usability. The new device enables a two-way simultaneous threshold RMT (IMT/PEP, GH INNOTEK, Busan, South Korea; Fig. 1), which has already proven its superior effect among various RMTs [11]. As the era of the COVID-19 pandemic continues, poor access to training centers and decreased completion of exercises are challenges in older individuals as well as in patients with respiratory diseases [13, 14]. Alternatively, home-based exercises could be effective to achieve adequate adherence, in the same way as conventional center-based exercises $[15,16]$. However, the effect and adherence to center-based RMT and home-based RMT have not yet been compared.

The aim of this present study was to confirm the efficacy of the new IMT/PEP device and to determine whether home-based training was better than rehabilitation center-based training in terms of improving the training adherence rate and effect. Therefore, in this randomized clinical trial, we investigate whether RMT using the new combined IMT/PEP device was non-inferior to that using the existing Threshold IMT (Philips Respironics Inc., Murrysville, PA, USA) device, and whether a home-based RMT program had non-inferior effects compared to center-based RMT.

\section{Methods}

\section{Study design}

This study was a four-group, multicenter, randomized, parallel, non-inferiority trial with concealed allocation and assessor blinding. All participants provided written informed consent. Ethics approval was obtained from 
the Institutional Review Boards (IRBs) of Pusan National University Hospital (IRB No. 1903-028-076) and Pusan National University Yangsan Hospital (IRB No. 03-2019006). All procedures of the study were performed in accordance with the amended Declaration of Helsinki. This study was registered at Clinical Research Information Service (No. KCT0003901).

\section{Recruitment and sample size}

Participants were recruited through a research recruitment flyer from welfare centers for older individuals in Busan, South Korea, from April 2019 to August 2020. Community-dwelling men over 60 years of age who were able to walk without a mobility aid were included. Exclusion criteria were as follows: known cardiopulmonary diseases that cause chest pain or dyspnea during activity; uncontrolled musculoskeletal pain; participation in other clinical trials within the last 4 weeks; and the presence of diseases, such as glaucoma, aneurysm, or pulmonary artery hypertension, which would prohibit the Valsalva maneuver [17]. The level of dyspnea during activity by which individuals were excluded from participation was more than 2 points on the modified Medical Research Council dyspnea scale [18]. The sample size was determined by calculations performed on data collected from a previous study [9]. Thus, 17 participants per group were necessary, based on a mean difference in the maximum inspiratory pressure (MIP) between exercises, with an alpha-risk of 0.05 and a beta-risk of 0.20 in a two-tailed test. To allow a $15 \%$ dropout rate, a sample size of 20 participants per group was finally determined.

\section{Randomization and interventions}

Prior to randomization, all participants underwent screening and familiarization with the training protocol before the baseline outcomes were evaluated. A blockrandomization process was performed with a block-size of 16, using computer-generated random allocation in Excel 2016 (Microsoft, Redmond, WA, USA). Random allocation was generated by an individual who did not participate in the study. The participants were randomly assigned in a 1:1:1:1 manner into the following groups, depending on the device allocated and the training site: IMT/PEP in the rehabilitation center (Group N-C), Threshold IMT in the rehabilitation center (Group I-C), IMT/PEP at home (Group N-H), and Threshold IMT at home (Group I-H).

For all participants, several practice tests were performed to correct possible training and learning effects, before the tests were conducted. All evaluations and training were conducted by different blinded researchers. The new IMT/PEP device used in this study had a threshold IMT range of $10-40 \mathrm{cmH}_{2} \mathrm{O}$ and PEP of 5-20 $\mathrm{cmH}_{2} \mathrm{O}$, with a resolution of $2 \mathrm{cmH}_{2} \mathrm{O}$. A variable loading can be set on the IMT/PEP device, providing flowindependent resistance to inspiration or expiration, by using two spring-loaded one-way valves. The valves of this device only opened when the pressure generated by the participant exceeded the set spring tension during inspiration and expiration. This concept is similar to that of the existing individual Threshold IMT and Threshold PEP devices (Philips Respironics Inc., Murrysville, PA, USA), but is designed in a way that allows simultaneous training of both IMT and PEP in one breathing cycle. Groups N-C and I-C visited the rehabilitation center twice a week to undergo supervised training over a period of 8 weeks. They also performed self-training at an individualized intensity twice a day at home for 8 weeks. Groups N-H and I-H performed the same RMT twice a day at home for 8 weeks, with only two supervised training sessions. For all participants, one self-training session was omitted (on the day of supervised training). A telephone interview was conducted 4 weeks after enrollment to confirm whether there were any problems with the training or device for the participants in Groups $\mathrm{N}-\mathrm{H}$ and $\mathrm{I}-\mathrm{H}$.

The inspiratory threshold for each device was set to $40 \%$ of the initial MIP of each participant. The maximum threshold of the device was $40 \mathrm{cmH}_{2} \mathrm{O}$. Considering that the average maximal expiratory pressure (MEP) was above $100 \mathrm{cmH}_{2} \mathrm{O}$ for those over 60 years of age [19], the expiratory threshold was set to $20 \mathrm{cmH}_{2} \mathrm{O}$ (the maximum load of the device) for groups using the combined IMT/PEP device (Groups N-C and N-H). All participants were instructed to inspire, from the residual volume, at a constant intensity and strength, to the point where they exceeded the threshold pressure. When they reached vital capacity, they held their breath for several seconds and then exhaled at a constant intensity for as long as possible. Each RMT set consisted of 10 deep and forceful breaths against the threshold pressure of the device. Participants were required to perform 10 sets twice a day, with 2 min of rest after each set. During the first training session, two RMT sets were practiced at half the target threshold to allow the patient to adapt to the devices. All participants kept a home exercise diary, which was used to check their training adherence, and all training in the rehabilitation center was conducted under the supervision of an experienced physiotherapist.

\section{Measurements}

All participants were assessed on the date of their first visit and at 1 week after completing the training program by an assessor blinded to the group allocation. Clinical 
and demographic data were collected, and the level of physical activity was evaluated using the International Physical Activity Questionnaire (IPAQ), adapted to older individuals [20]. The primary outcomes in this study were MIP and MEP, and the secondary outcomes were forced vital capacity (FVC) and forced expiratory volume in the first second $\left(\mathrm{FEV}_{1}\right)$, peak cough flow (PCF), ultrasoundbased diaphragm thickness, predicted $\mathrm{VO}_{2}$ peak, IPAQ score, electromyography activities of the sternocleidomastoid muscle, and skeletal muscle mass and phase angle by bioimpedance analysis (BIA).

\section{Primary outcomes}

MIP, MEP, and pulmonary functions were evaluated in a standardized method using a desktop spirometer Pony FX (Cosmed, Rome, Italy) [21, 22]. MIP and MEP, reflect inspiratory and expiratory muscle strength, respectively. Measurements were obtained, with participants in a sitting position, using a flange-type mouthpiece. The MIP was acquired from one maximal inspiration, starting from close to the residual volume. The MEP was obtained from the maximal expiration, starting from close to the vital capacity. At least five measurements were obtained, and when reproducible measurements with a difference of less than $10 \%$ were obtained, the highest three measurements were recorded [23]. Prediction of MIP and MEP was calculated using the following reference eqs [19].:

$$
\begin{aligned}
& \text { Male MIP reference }=120-(0.41 \times \text { age }) \\
& \text { Male MEP reference }=174-(0.83 \times \text { age })
\end{aligned}
$$

\section{Secondary outcomes}

The PCF was measured with a Micro Peak-flow meter (Micro Medical, Calabasas, CA, USA.) The result recorded was the maximum value obtained from three trials of a short and forceful expiration after a maximum inspiration [24]. FVC and $\mathrm{FEV}_{1}$ were measured from maximum inspiration and expiration after taking three normal breaths, in accordance with the following reference eqs [25]..
[26]. Participants were instructed to breathe quietly and spontaneously in the supine position, and the right diaphragm thickness at the end of quiet expiration (Texp) and at the end of quiet inspiration (Tins) was measured in $\mathrm{mm}$. A total of five measurements were obtained, and the three values, excluding the maximum and minimum values, were recorded.

The Chester step test is an effective and simple method for evaluation of aerobic capacity [27]. As a submaximal test, steps can be performed at various heights with both feet according to a metronome rhythm. In this study, a 20 -cm step box was used for participants over 60 -yearsold. In stage 1 , steps were performed at a speed of 60 beats per minute, and the speed was increased by 20 beats per minute every $2 \mathrm{~min}$. Heart rate, oxygen saturation, and the Borg Category/Ratio-10 Dyspnea Scale ${ }^{\circledR}$ were measured before and at the end of each stage. The predicted oxygen consumption based on the heart rate at each stage was calculated [28]. Phase angles and skeletal muscle mass were quantified in participants using a segmental multi-frequency BIA system (S10, InBody Co., Ltd., Seoul, South Korea). Touch-type electrodes were attached between the participants' ankles and on the middle finger and thumb of both hands. Participants rested in a supine position for several minutes before the BIA measurements were taken. The phase angles of each segment of the body were automatically calculated at frequencies of 5,50 , and $250 \mathrm{kHz}$ by the BIA system's software. Among the many variables, we analyzed the $50-\mathrm{kHz}$ whole-body phase angle.

To measure the muscle activity required for the target pressures, during the first and last supervised training for effective RMT, a surface electromyography (sEMG) device was also applied. The single-channel sEMG device (PSL-EMG-Tr1; PhysioLab Co., Ltd., Busan, South Korea) was set to a sampling rate of $30,000 \mathrm{~Hz}$, and signals were amplified within a $3-2000-\mathrm{Hz}$ bandwidth [29]. Conductive adhesive hydrogel electrodes (Covidien, Minneapolis, MN, USA) were placed parallel to the left sternocleidomastoid (SCM) fibers according to the recommendation [30]. Before the sEMG measurement, the participants sat upright on an adjustable-height stool, with a neutral head posture, maintaining the normal cur-

$$
\begin{gathered}
\text { FVC in male (liter) }=-4.8434-0.00008633 \times \text { Age }^{2}+0.05292 \times \text { Height }(\mathrm{cm})+0.01095 \times \text { Weight }(\mathrm{kg}) \\
\text { FEV1 in male (liter) }=-3.4132-0.0002484 \times \text { Age }^{2}+0.04578 \times \text { Height }(\mathrm{cm})
\end{gathered}
$$

Ultrasound (Z.ONE, ZONARE, Mountain View, CA, USA) was used to measure diaphragm thickness, between the 8th and 9th ribs of the anterior and midaxillary lines, using a $12-\mathrm{MHz}$ linear probe in B-mode vature of the spine. Afterward, they held the RMT training device with the right hand, and muscle activity was measured during RMT. The muscle activity of the SCM used in forceful inspiration was presented in real-time 
through a tablet screen, and feedback on the proper use of respiratory muscle during training was available. The root mean square (RMS) reflected the activities of the motor unit in muscle contraction [31]. The RMS values of the recorded sEMG obtained from the initial feedback training and follow-up test were used for analysis. To standardize the measurement, the mean RMS of the left SCM muscle obtained in the fifth set of training was calculated for all participants. The mean RMS obtained in the middle $2 \mathrm{~s}$ of each inspiration was analyzed.

\section{Statistical analysis}

A minimal clinically important significance (MCID) of $11 \mathrm{cmH}_{2} \mathrm{O}$ in the MIP of the Threshold IMT group was used to confirm non-inferiority [31]. The IMT/PEP groups were considered non-inferior to the Threshold IMT groups if the upper MIP limit did not exceed the 95\% confidence interval in the Threshold IMT group. In addition, variables were compared between the center-training and the home-training groups to identify differences according to the training protocol when using the same device. The result of the baseline characteristics and analyzed outcomes are presented as mean \pm standard deviation. We used an intentionto-treat approach for the primary analysis. One-way analysis of variance was used to identify demographic differences among the four groups. Normality of data distribution was verified through the Shapiro-Wilk test. Comparison of values pre- and post-training in each group were performed via the paired $t$-test and the Wilcoxon signed-rank test. The independent $t$-test and Mann-Whitney test were used to compare values between groups. A $p$-value $<0.05$ was considered statistically significant. All statistical analyses were performed using SPSS Statistics for Windows (version 22, Chicago, IL, USA).

\section{Results}

Eighty participants were randomized equally into four groups. Groups N-C and N-H used the IMT/PEP device and Groups I-C and I-H used the Threshold

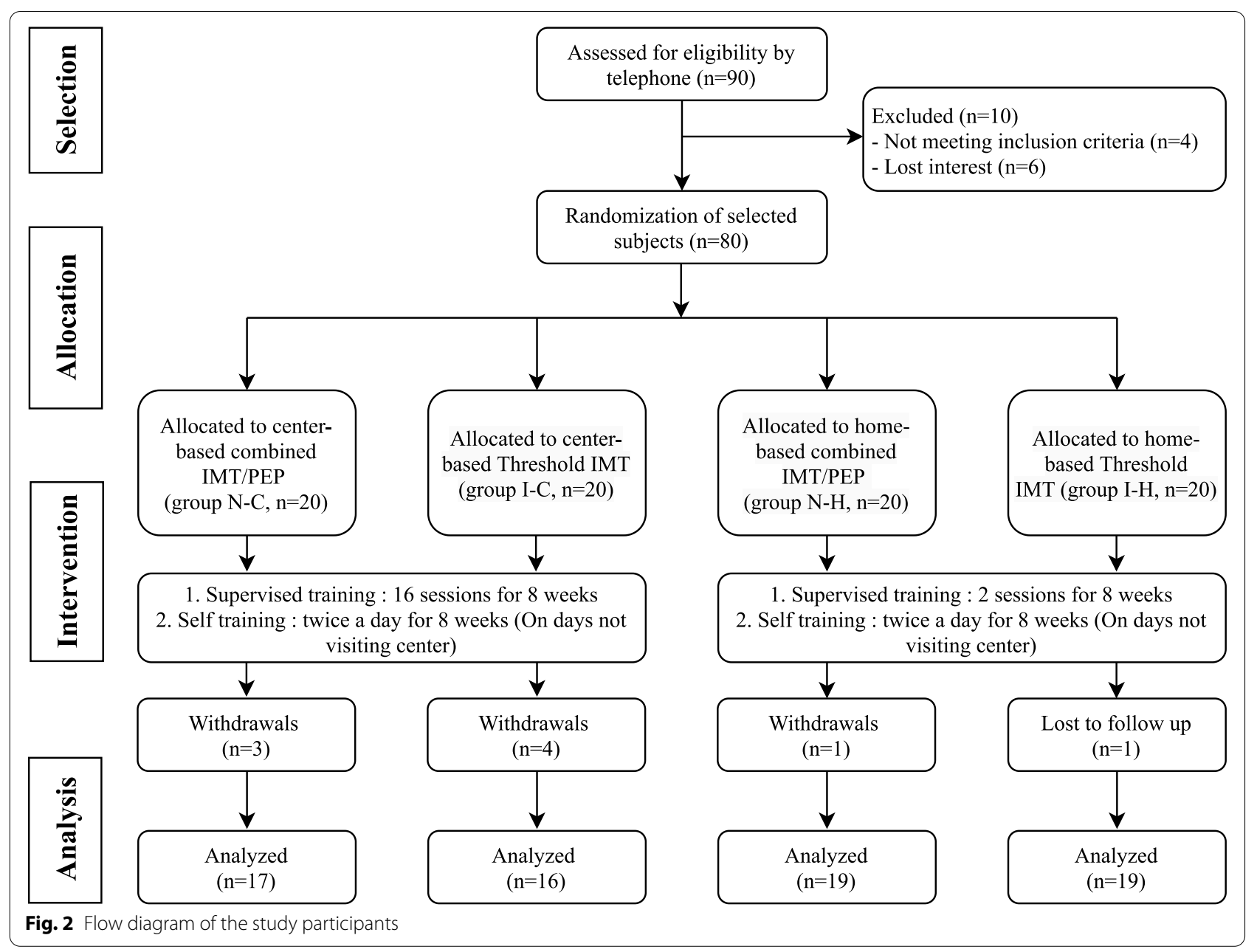


Table 1 Demographics and baseline characteristics of the participants

\begin{tabular}{|c|c|c|c|c|c|}
\hline Parameters & $\begin{array}{l}\text { Group N-C } \\
(\mathrm{n}=20)\end{array}$ & $\begin{array}{l}\text { Group I-C } \\
(n=20)\end{array}$ & $\begin{array}{l}\text { Group N-H } \\
(n=20)\end{array}$ & $\begin{array}{l}\text { Group I-H } \\
(n=20)\end{array}$ & $P$ value \\
\hline Age (years) & $73.00 \pm 5.36$ & $73.86 \pm 3.46$ & $74.32 \pm 4.82$ & $71.95 \pm 5.09$ & 0.374 \\
\hline Weight (kg) & $68.20 \pm 8.94$ & $67.55 \pm 9.66$ & $67.70 \pm 10.44$ & $71.91 \pm 9.24$ & 0.574 \\
\hline Height (m) & $1.64 \pm 0.04$ & $1.63 \pm 0.06$ & $1.66 \pm 0.06$ & $1.67 \pm 0.04$ & 0.434 \\
\hline BMI $\left(\mathrm{kg} / \mathrm{m}^{2}\right)$ & $25.18 \pm 3.08$ & $24.94 \pm 2.66$ & $24.57 \pm 2.75$ & $25.78 \pm 2.98$ & 0.684 \\
\hline $\mathrm{FVC}(\mathrm{L})$ & $3.22 \pm 0.51$ & $3.19 \pm 0.57$ & $3.04 \pm 0.46$ & $3.25 \pm 0.58$ & 0.403 \\
\hline FVC (\% predicted) & $99.23 \pm 14.28$ & $100.28 \pm 16.20$ & $94.15 \pm 16.13$ & $95.36 \pm 13.89$ & 0.583 \\
\hline $\mathrm{FEV}_{1}(\mathrm{~L})$ & $2.48 \pm 0.41$ & $2.42 \pm 0.59$ & $2.31 \pm 0.49$ & $2.46 \pm 0.59$ & 0.653 \\
\hline $\mathrm{FEV}_{1}(\%$ predicted $)$ & $112.17 \pm 16.71$ & $110.35 \pm 27.18$ & $106.31 \pm 24.73$ & $105.84 \pm 21.09$ & 0.788 \\
\hline $\mathrm{FEV}_{1} / \mathrm{FVC}(\%)$ & $76.17 \pm 5.55$ & $74.57 \pm 9.61$ & $75.57 \pm 11.28$ & $74.89 \pm 9.71$ & 0.734 \\
\hline$P C F(L / m i n)$ & $438.82 \pm 74.57$ & $414.28 \pm 96.13$ & $426.31 \pm 87.63$ & $424.21 \pm 111.22$ & 0.962 \\
\hline $\operatorname{MIP}\left(\mathrm{cmH}_{2} \mathrm{O}\right)$ & $93.05 \pm 23.81$ & $78.35 \pm 15.43$ & $77.99 \pm 18.01$ & $85.33 \pm 30.11$ & 0.316 \\
\hline MIP (\% predicted) & $103.38 \pm 26.78$ & $87.42 \pm 17.68$ & $87.11 \pm 20.23$ & $94.13 \pm 32.45$ & 0.313 \\
\hline $\operatorname{MEP}\left(\mathrm{cmH}_{2} \mathrm{O}\right)$ & $82.54 \pm 24.11$ & $96.07 \pm 21.53$ & $92.07 \pm 18.03$ & $99.00 \pm 29.27$ & 0.100 \\
\hline MEP (\% predicted) & $72.70 \pm 20.61$ & $85.26 \pm 18.98$ & $81.91 \pm 15.42$ & $86.55 \pm 24.90$ & 0.119 \\
\hline $\mathrm{VO}_{2}$ peak $(\mathrm{ml} / \mathrm{kg} / \mathrm{min})$ & $33.85 \pm 5.55$ & $29.01 \pm 5.58$ & $35.76 \pm 9.45$ & $34.52 \pm 6.29$ & 0.466 \\
\hline Adherence rate (\% sessions completed) & $91.94 \pm 21.93$ & $99.50 \pm 1.87$ & $92.37 \pm 14.35$ & $92.05 \pm 20.30$ & 0.491 \\
\hline RMS (uV) & $49.69 \pm 20.56$ & $46.27 \pm 19.86$ & $55.79 \pm 31.96$ & $42.37 \pm 22.27$ & 0.416 \\
\hline Right diaphragm thickness at end inspiration (mm) & $2.90 \pm 0.82$ & $3.24 \pm 0.94$ & $2.63 \pm 0.77$ & $2.88 \pm 0.59$ & 0.207 \\
\hline $\mathrm{SMI}\left(\mathrm{kg} / \mathrm{m}^{2}\right)$ & $8.88 \pm 0.89$ & $8.90 \pm 0.73$ & $8.74 \pm 0.72$ & $9.13 \pm 0.69$ & 0.453 \\
\hline Bioimpedance-derived phase angle & $5.84 \pm 0.71$ & $5.84 \pm 0.55$ & $5.90 \pm 0.50$ & $6.16 \pm 0.51$ & 0.178 \\
\hline IPAQ (MET-min/week) & $2998.23 \pm 3135.65$ & $2365.92 \pm 2286.87$ & $3071.89 \pm 2164.56$ & $3672.10 \pm 4046.08$ & 0.455 \\
\hline IPAQ (activity level) & $2.11 \pm 0.48$ & $2.21 \pm 0.57$ & $2.36 \pm 0.49$ & $2.10 \pm 0.73$ & 0.422 \\
\hline
\end{tabular}

Continuous variables are reported as mean \pm standard deviation

Abbreviations: $B M I$ body mass index, FVC forced vital capacity, FEV forced expiratory volume in the first second, $P C F$ peak cough flow, MIP maximal expiratory pressure, $M E P$ maximal expiratory pressure, $V \mathrm{O}_{2}$ peak peak oxygen uptake, $R M S$ root mean square, $S M I$ skeletal muscle index, IPAQ International Physical Activity Questionnaire

IMT (Fig. 2). During the 8-week intervention, seven (17.5\%) participants in the center-based groups and two (5\%) in the home-based groups withdrew from the study. Reasons for the dropout included a loss to follow-up, loss of interest in training, or participants being too busy. Table 1 presents the demographics and baseline outcomes of each group. There were no statistically significant differences in demographic variables among the four groups.

\section{MIP and MEP}

In the pre- and post-assessment of the 8-week intervention, the MIP and MEP were significantly improved in Groups N-C $(P=0.001$ and $P<0.001$ respectively $)$ and N-H $(P<0.001$ and $P=0.008$, respectively $)$, but in Groups I-C $(\mathrm{P}=0.001$ and $P=0.874)$ and $\mathrm{I}-\mathrm{H}(P<0.001$ and $P=0.136)$, significant improvements were identified only in the MIP (Table 2). As illustrated in Fig. 3, the lower limit of the $95 \%$ confidence interval was within the non-inferiority margin of the MIP between Groups N-C/I-C and N-H/I-H. Specifically for the
MIP, improvements by training were identified in all groups, and there were no statistically significant differences between devices and training protocols. In the MEP, statistically significant differences were identified only between Groups N-C and I-C $(P=0.002)$ (Table 2 , Fig. 4).

\section{Exercise adherence}

There was no significant difference in the training adherence rate between the home- and center-based training groups. Adherence rates in each group ranged from 91 to 99\% (Table 1).

\section{Diaphragm thickness and PCF}

Significant increases in the right diaphragm thickness at end-tidal volume were identified in Groups N-C $(P=0.026), \mathrm{N}-\mathrm{H}(P=0.018)$, and $\mathrm{I}-\mathrm{H}(P=0.022)$. Groups $\mathrm{N}-\mathrm{H}(P=0.010)$ and $\mathrm{I}-\mathrm{H}(P=0.007)$ showed significant improvements in PCF (Table 3). 
Table 2 Mean changes and mean differences of MIP and MEP after training within and between groups

\begin{tabular}{|c|c|c|c|c|c|c|c|c|}
\hline \multirow{3}{*}{ Outcomes } & \multicolumn{2}{|l|}{ Group N-C $(n=17)$} & \multicolumn{2}{|l|}{ Group I-C $(n=16)$} & \multicolumn{2}{|l|}{ Group N-H $(n=19)$} & \multicolumn{2}{|l|}{ Group I-H $(n=19)$} \\
\hline & Change from baseline & $P$ value & Change from baseline & $P$ value & Change from baseline & $P$ value & Change from baseline & $P$ value \\
\hline & & ES & & ES & & ES & & ES \\
\hline \multirow{2}{*}{$\begin{array}{l}\mathrm{MIP} \\
\left(\mathrm{cmH}_{2} \mathrm{O}\right)\end{array}$} & \multirow{2}{*}{$\begin{array}{l}18.03 \pm 17.87 \\
(9.15 \text { to } 26.9)\end{array}$} & $0.001^{*}$ & \multirow{2}{*}{$\begin{array}{l}12.66 \pm 12.76 \\
(5.86 \text { to } 19.46)\end{array}$} & $0.001^{*}$ & \multirow{2}{*}{$\begin{array}{l}15.65 \pm 15.96 \\
\text { (7.95 to } 23.34)\end{array}$} & $0.000^{*}$ & \multirow{2}{*}{$\begin{array}{l}10.17 \pm 9.85 \\
(5.42 \text { to } 14.92)\end{array}$} & $0.000^{*}$ \\
\hline & & 1.0 & & 0.9 & & 0.9 & & 1.0 \\
\hline \multirow{2}{*}{$\begin{array}{l}\text { MIP } \\
\text { (\% predicted) }\end{array}$} & \multirow{2}{*}{$\begin{array}{l}20.34 \pm 20.35 \\
\text { (9.87 to } 30.80 \text { ) }\end{array}$} & $0.001^{*}$ & \multirow{2}{*}{$\begin{array}{l}14.04 \pm 14.06 \\
(6.55 \text { to } 21.53\end{array}$} & $0.001^{*}$ & \multirow{2}{*}{$\begin{array}{l}17.42 \pm 17.82 \\
(8.83 \text { to } 26.01)\end{array}$} & $0.000^{*}$ & \multirow{2}{*}{$\begin{array}{l}11.20 \pm 10.75 \\
(4.54 \text { to } 6.01)\end{array}$} & $0.000^{*}$ \\
\hline & & 1.0 & & 0.9 & & 0.9 & & 1.0 \\
\hline \multirow{2}{*}{$\begin{array}{l}\mathrm{MEP} \\
\left(\mathrm{cmH}_{2} \mathrm{O}\right)\end{array}$} & \multirow{2}{*}{$\begin{array}{l}25.96 \pm 20.23 \\
(15.89 \text { to } 36.02)\end{array}$} & $0.000^{*}$ & \multirow{2}{*}{$\begin{array}{l}0.87 \pm 21.66 \\
(-10.66 \text { to } 12.41)\end{array}$} & $0.874^{*}$ & \multirow{2}{*}{$\begin{array}{l}14.75 \pm 21.58 \\
(4.35 \text { to } 25.15)\end{array}$} & \multirow{2}{*}{$0.008^{* *}$} & \multirow{2}{*}{$\begin{array}{l}8.08 \pm 22.57 \\
(-2.79 \text { to } 18.97)\end{array}$} & $0.136^{*}$ \\
\hline & & 1.2 & & 0.1 & & & & 0.3 \\
\hline \multirow{3}{*}{$\begin{array}{l}\text { MEP } \\
\text { (\% predicted) }\end{array}$} & \multirow{2}{*}{$\begin{array}{l}23.00 \pm 18.23 \\
(13.63 \text { to } 32.38)\end{array}$} & $0.000^{*}$ & \multirow{2}{*}{$\begin{array}{l}0.95 \pm 19.57 \\
(-9.47 \text { to } 11.38)\end{array}$} & $0.848^{*}$ & \multirow{2}{*}{$\begin{array}{l}13.18 \pm 19.00 \\
(-4.02 \text { to } 22.34)\end{array}$} & \multirow{2}{*}{$0.007^{* *}$} & \multirow{2}{*}{$\begin{array}{l}6.96 \pm 20.07 \\
(-2.70 \text { to } 16.64)\end{array}$} & $0.148^{*}$ \\
\hline & & 1.2 & & 0.1 & & & & 0.3 \\
\hline & \multicolumn{2}{|l|}{ Groups N-C and I-C } & \multicolumn{2}{|l|}{ Groups N-C and N-H } & \multicolumn{2}{|l|}{ Groups $\mathrm{N}-\mathrm{H}$ and $\mathrm{I}-\mathrm{H}$} & \multicolumn{2}{|l|}{ Groups I-C and I-H } \\
\hline \multirow{2}{*}{$\begin{array}{l}\mathrm{MIP} \\
\left(\mathrm{cmH}_{2} \mathrm{O}\right)\end{array}$} & \multirow{2}{*}{$\begin{array}{l}5.77 \pm 5.53 \\
(-5.52 \text { to } 17.05)\end{array}$} & $0.305+$ & \multirow{2}{*}{$\begin{array}{l}2.78 \pm 5.72 \\
(-8.84 \text { to } 14.40)\end{array}$} & $0.630+$ & \multirow{2}{*}{$\begin{array}{l}5.48 \pm 4.30 \\
(-3.31 \text { to } 14.27)\end{array}$} & $0.212+$ & $2.49 \pm 3.82$ & $0.519+$ \\
\hline & & 0.3 & & 0.1 & & 0.4 & & 0.2 \\
\hline MIP & $5.38 \pm 9.04$ & $0.556+$ & $2.92 \pm 6.36$ & $0.649+$ & $6.22 \pm 4.76$ & $0.203+$ & $3.75 \pm 7.43$ & $0.617+$ \\
\hline (\% predicted) & $(-13.19$ to 23.96$)$ & 0.3 & & 0.1 & & 0.4 & $(-11.37$ to 18.87$)$ & 0.2 \\
\hline MEP & $25.14 \pm 7.40$ & $0.002 \dagger$ & $11.27 \pm 7.09$ & $0.121+\dagger$ & $6.66 \pm 7.17$ & $0.359+\dagger$ & $-7.22 \pm 7.52$ & $0.344 \dagger$ \\
\hline$\left(\mathrm{cmH}_{2} \mathrm{O}\right)$ & (10.05 to 40.24$)$ & 1.9 & & & & & & 0.3 \\
\hline MEP & $22.06 \pm 6.58$ & $0.002+$ & $9.82 \pm 6.22$ & $0.124+\dagger$ & $6.22 \pm 6.34$ & $0.334+\dagger$ & $-6.02 \pm 6.73$ & $0.378+$ \\
\hline (\% predicted) & (8.64 to 35.48 ) & 1.1 & (-2.83 to 22.48$)$ & & & & & \\
\hline
\end{tabular}

Continuous variables are reported as mean \pm standard deviation ( $95 \%$ confidence interval)

*Paired $t$-test. ** Wilcoxon signed-rank test. †Independent $t$-test. †† Mann-Whitney test

Abbreviations: MIP maximal expiratory pressure, MEP maximal expiratory pressure, ES Effect size

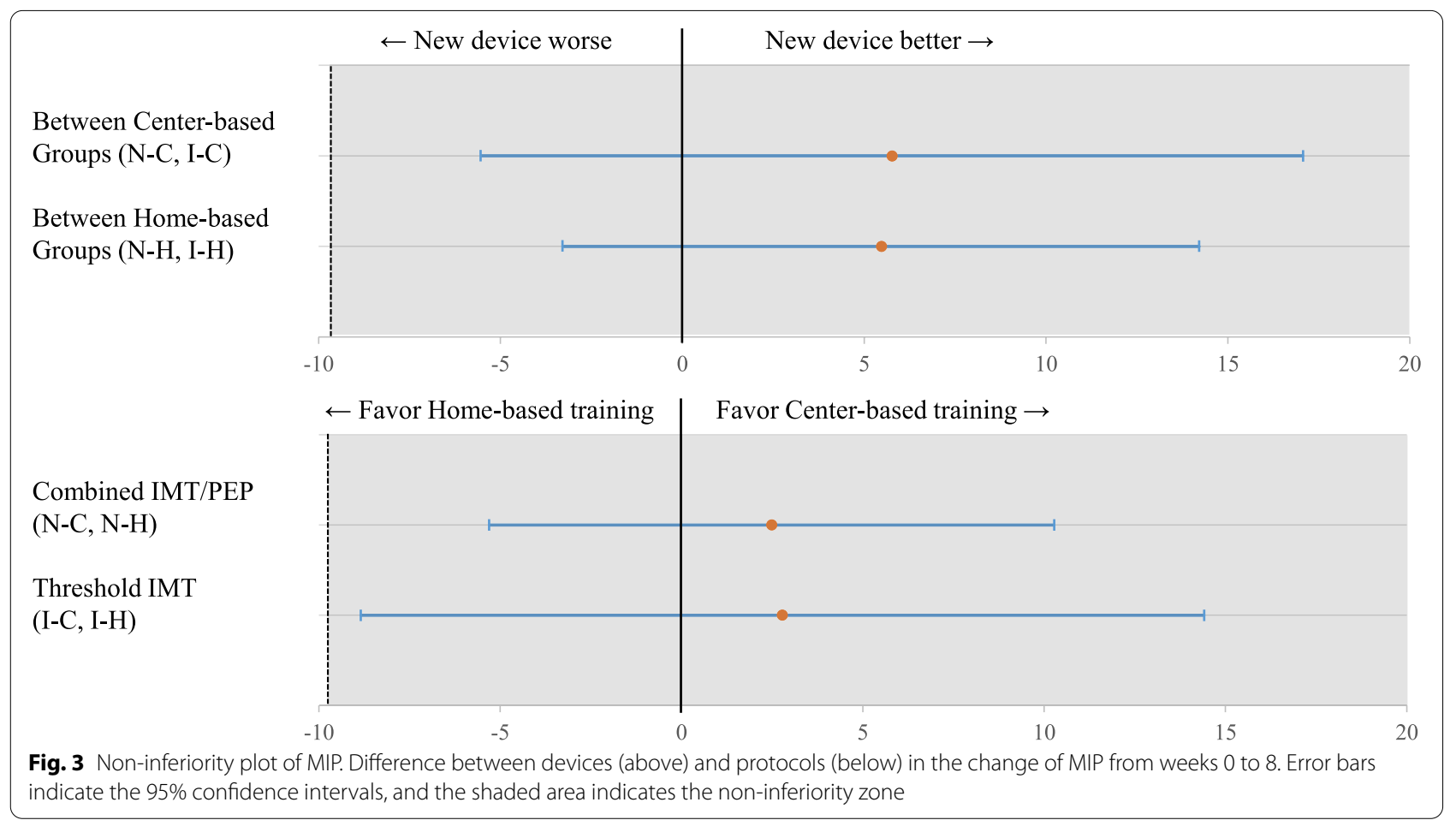




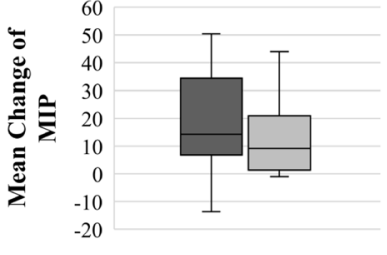

N-C I-C

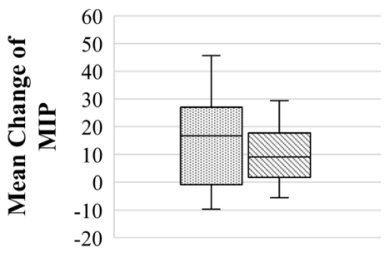

N-H I-H

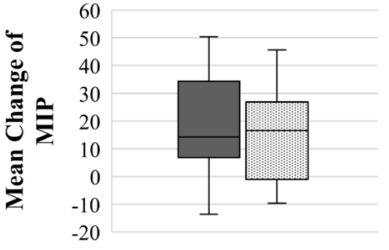

N-C N-H

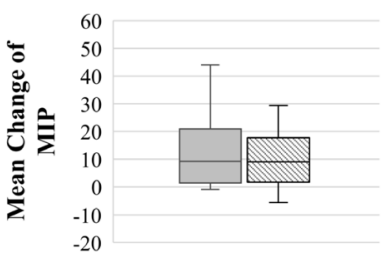

I-C I-H

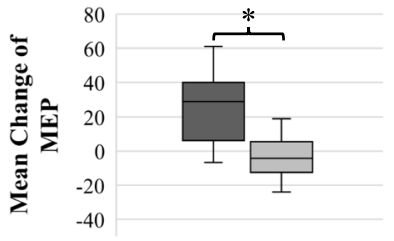

N-C I-C

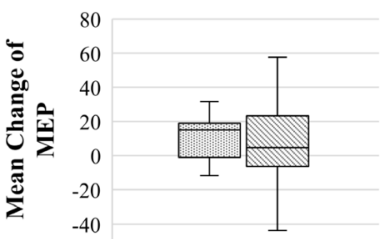

N-H I-H

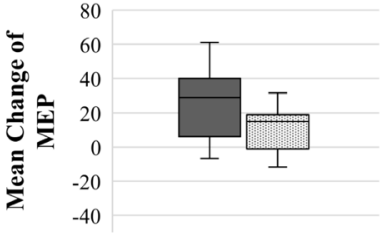

N-C N-H

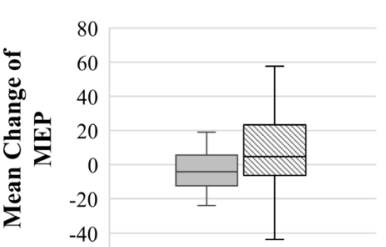

I-C I-H

Fig. 4 Mean changes in MIP and MEP after 8 weeks of training between devices or protocols. ${ }^{*} P=0.002$

Table 3 Mean changes in secondary outcomes after 8 weeks of inspiratory muscle training

\begin{tabular}{|c|c|c|c|c|c|c|c|c|}
\hline & $\begin{array}{l}\text { Group N-C } \\
(n=17)\end{array}$ & & $\begin{array}{l}\text { Group I-C } \\
(n=16)\end{array}$ & & $\begin{array}{l}\text { Group N-H } \\
(n=19)\end{array}$ & & $\begin{array}{l}\text { Group I-H } \\
(n=19)\end{array}$ & \\
\hline Outcomes & $\begin{array}{l}\text { Change from } \\
\text { baseline }\end{array}$ & $\begin{array}{l}P \text { value } \\
\text { ES }\end{array}$ & $\begin{array}{l}\text { Change from } \\
\text { baseline }\end{array}$ & $\begin{array}{l}P \text { value } \\
\text { ES }\end{array}$ & $\begin{array}{l}\text { Change from } \\
\text { baseline }\end{array}$ & $\begin{array}{l}P \text { value } \\
\text { ES }\end{array}$ & $\begin{array}{l}\text { Change from } \\
\text { baseline }\end{array}$ & $\begin{array}{l}P \text { value } \\
\text { ES }\end{array}$ \\
\hline $\begin{array}{l}\text { Right diaphragm } \\
\text { thickness at end } \\
\text { inspiration (mm) }\end{array}$ & $\begin{array}{l}0.70 \pm 1.17 \\
\text { (0.09 to } 1.30)\end{array}$ & $\begin{array}{l}0.026^{*} \\
0.5\end{array}$ & $\begin{array}{l}0.20 \pm 1.27 \\
(-0.47 \text { to } 0.88)\end{array}$ & $\begin{array}{l}0.527 \\
0.1\end{array}$ & $\begin{array}{l}0.50 \pm 0.83 \\
(0.09 \text { to } 0.90)\end{array}$ & $\begin{array}{l}0.018^{*} \\
0.6\end{array}$ & $\begin{array}{l}0.62 \pm 1.09 \\
(0.10 \text { to } 1.15)\end{array}$ & $\begin{array}{l}0.022^{*} \\
0.5\end{array}$ \\
\hline $\mathrm{BMI}\left(\mathrm{kg} / \mathrm{m}^{2}\right)$ & $\begin{array}{l}-0.99 \pm 2.85 \\
(-2.46 \text { to } 0.47)\end{array}$ & $\begin{array}{l}0.169 \\
0.3\end{array}$ & $\begin{array}{l}0.78 \pm 1.40 \\
(0.00 \text { to } 1.56)\end{array}$ & $\begin{array}{l}0.048^{*} \\
0.5\end{array}$ & $\begin{array}{l}0.19 \pm 0.85 \\
(-0.21 \text { to } 0.60)\end{array}$ & $\begin{array}{l}0.340 \\
0.2\end{array}$ & $\begin{array}{l}0.23 \pm 1.00 \\
(-0.24 \text { to } 0.71)\end{array}$ & $\begin{array}{l}0.318 \\
0.2\end{array}$ \\
\hline FVC (\% predicted) & $\begin{array}{l}2.05 \pm 4.09 \\
(0.04 \text { to } 4.16)\end{array}$ & $\begin{array}{l}0.055 \\
0.5\end{array}$ & $\begin{array}{l}3.18 \pm 6.96 \\
(-0.52 \text { to } 6.90)\end{array}$ & $\begin{array}{l}0.087 \\
0.4\end{array}$ & $\begin{array}{l}-1.63 \pm 19.24 \\
(-10.90 \text { to } 7.64)\end{array}$ & $\begin{array}{l}0.716 \\
0.1\end{array}$ & $\begin{array}{l}0.57 \pm 8.00 \\
(-3.28 \text { to } 4.43)\end{array}$ & $\begin{array}{l}0.756 \\
0.1\end{array}$ \\
\hline FEV1 (\% predicted) & $\begin{array}{l}-1.00 \pm 4.25 \\
(-3.18 \text { to } 1.18)\end{array}$ & $\begin{array}{l}0.347 \\
0.2\end{array}$ & $\begin{array}{l}2.25 \pm 14.59 \\
(-5.52 \text { to } 10.02)\end{array}$ & $\begin{array}{l}0.547 \\
0.1\end{array}$ & $\begin{array}{l}4.10 \pm 19.80 \\
(-5.44 \text { to } 13.65)\end{array}$ & $\begin{array}{l}0.378 \\
0.2\end{array}$ & $\begin{array}{l}3.31 \pm 10.23 \\
(-1.61 \text { to } 8.24)\end{array}$ & $\begin{array}{l}0.175 \\
0.3\end{array}$ \\
\hline PCF (L/min) & $\begin{array}{l}6.11 \pm 55.00 \\
(-21.24 \text { to } 31.46)\end{array}$ & $\begin{array}{l}0.643 \\
0.1\end{array}$ & $\begin{array}{l}3.12 \pm 34.19 \\
(-15.09 \text { to } 21.34)\end{array}$ & $\begin{array}{l}0.720 \\
0.1\end{array}$ & $\begin{array}{l}23.68 \pm 35.77 \\
(6.43 \text { to } 40.92)\end{array}$ & $\begin{array}{l}0.010^{*} \\
0.6\end{array}$ & $\begin{array}{l}29.47 \pm 42.48 \\
(8.99 \text { to } 49.95)\end{array}$ & $\begin{array}{l}0.007^{*} \\
0.6\end{array}$ \\
\hline RMS (uV) & $\begin{array}{l}9.76 \pm 78.75 \\
(-5.02 \text { to } 24.54)\end{array}$ & $\begin{array}{l}0.181 \\
0.1\end{array}$ & $\begin{array}{l}6.23 \pm 22.36 \\
(-5.68 \text { to } 18.15)\end{array}$ & $\begin{array}{l}0.283 \\
0.2\end{array}$ & $\begin{array}{l}8.23 \pm 21.45 \\
(-2.10 \text { to } 18.57)\end{array}$ & $\begin{array}{l}0.112 \\
0.3\end{array}$ & $\begin{array}{l}7.89 \pm 29.96 \\
(-6.54 \text { to } 22.34)\end{array}$ & $\begin{array}{l}0.266 \\
0.2\end{array}$ \\
\hline SMl & $\begin{array}{l}-0.06 \pm 0.33 \\
(-0.23 \text { to } 0.10)\end{array}$ & $\begin{array}{l}0.711 \\
0.1\end{array}$ & $\begin{array}{l}0.03 \pm 0.34 \\
(-0.15 \text { to } 0.22)\end{array}$ & $\begin{array}{l}0.711 \\
0.1\end{array}$ & $\begin{array}{l}0.10 \pm 0.26 \\
(-0.02 \text { to } 0.22)\end{array}$ & $\begin{array}{l}0.114 \\
0.3\end{array}$ & $\begin{array}{l}0.03 \pm 0.31 \\
(-0.11 \text { to } 0.18)\end{array}$ & $\begin{array}{l}0.663 \\
0.1\end{array}$ \\
\hline $\begin{array}{l}\text { Bioimpedance- } \\
\text { derived phase angle }\end{array}$ & $\begin{array}{l}0.06 \pm 0.32 \\
(-0.10 \text { to } 0.23)\end{array}$ & $\begin{array}{l}0.428 \\
0.1\end{array}$ & $\begin{array}{l}0.12 \pm 0.32 \\
(-0.05 \text { to } 0.30)\end{array}$ & $\begin{array}{l}0.152 \\
0.3\end{array}$ & $\begin{array}{l}-0.08 \pm 0.30 \\
(-0.22 \text { to } 0.06)\end{array}$ & $\begin{array}{l}0.240 \\
0.2\end{array}$ & $\begin{array}{l}0.06 \pm 0.30 \\
(-3.28 \text { to } 4.43)\end{array}$ & $\begin{array}{l}0.756 \\
0.2\end{array}$ \\
\hline $\begin{array}{l}\text { IPAQ (MET-min/ } \\
\text { week) }\end{array}$ & $\begin{array}{l}-236.82 \pm 2294.48 \\
(-1416.53 \text { to } 942.88)\end{array}$ & $\begin{array}{l}0.676 \\
0.1\end{array}$ & $\begin{array}{l}-229.06 \pm 2018.41 \\
(-1304.60 \text { to } 846.47)\end{array}$ & $\begin{array}{l}0.656 \\
0.1\end{array}$ & $\begin{array}{l}-165.73 \pm 1745.60 \\
(-1007.09 \text { to } 675.61)\end{array}$ & $\begin{array}{l}0.684 \\
0.1\end{array}$ & $\begin{array}{l}-277.84 \pm 2939.75 \\
(-1694.75 \text { to } \\
1139.07)\end{array}$ & $\begin{array}{l}0.685 \\
0.1\end{array}$ \\
\hline $\begin{array}{l}\mathrm{VO}_{2} \text { peak (ml/kg/ } \\
\text { min) }\end{array}$ & $\begin{array}{l}1.44 \pm 5.88 \\
(-1.48 \text { to } 4.36)\end{array}$ & $\begin{array}{l}0.312 \\
0.2\end{array}$ & $\begin{array}{l}0.73 \pm 5.26 \\
(-2.06 \text { to } 3.54)\end{array}$ & $\begin{array}{l}0.583 \\
0.1\end{array}$ & $\begin{array}{l}-1.64 \pm 7.63 \\
(-5.32 \text { to } 2.03)\end{array}$ & $\begin{array}{l}0.361 \\
0.2\end{array}$ & $\begin{array}{l}-1.76 \pm 7.38 \\
(-5.32 \text { to } 1.79)\end{array}$ & $\begin{array}{l}0.312 \\
0.5\end{array}$ \\
\hline
\end{tabular}

Continuous variables are reported as mean \pm standard deviation ( $95 \%$ confidence interval)

Abbreviations: $B M I$ body mass index, FVC forced vital capacity, $F E V$, forced expiratory volume in the first second, $P C F$ peak cough flow, $R M S$ root mean square, SMI skeletal muscle index, IPAQ International Physical Activity Questionnaire; $\mathrm{VO}_{2}$ peak, peak oxygen uptake

\section{Adverse events}

No adverse events related to the intervention were reported among the participants during the clinical trial, except for one patient with a transient headache. Although this possible mild adverse event appeared at the end of the first training session, the hemodynamic 
response was normal, and the symptom was relieved within a 5-min break. In this participant, the intensity of the RMT was initiated at $50 \%$ of the target and was then gradually increased, with no subsequent symptoms.

\section{Discussion}

\section{MIP, MEP, and exercise adherence}

Until now, no previous randomized, non-inferiority trial has attempted to validate the effect of the newly developed IMT/PEP device for older men. In previous studies, it was typically proposed that RMT should be performed for about $30 \mathrm{~min}$, or two 15 -min sessions daily [32-34]. In this study, the session consisted of performing 10 sets of 10 breaths, in consideration of the participant's compliance and for the ease of calculating the number of repetitions. The protocol involved training for 8 weeks, for two sessions a day. The primary finding of this study was that, after 8 weeks of training, inspiratory muscle strengthening via the new IMT/PEP device was not inferior to that achieved using the Threshold IMT device. Furthermore, the IMT/PEP device resulted in significant improvement in MEP, which is related to the power of expiratory muscles, which was not observed in the Threshold IMT training groups. Of course, significant MEP improvements could have been expected if the additional conventional Threshold PEP device (Philips Respironics Inc., Murrysville, PA, USA) was also included for use by Groups I-C and I-H. However, the use of two separate devices, namely, the Threshold IMT and Threshold PEP, is likely to double the training time and complicate the training procedure. Although multiple factors affect training adherence [35], a previous study has shown that a shorter training time has a positive effect on training adherence [36]. From this perspective, we used only the Threshold IMT device in Groups I-C and I-H to standardize the time spent on training. We hypothesized that simultaneous inspiration and expiration training within a single breath would yield additional benefits. However, there were no statistically significant differences in the mean MIP between groups before and after training, as compared to the results when the conventional Threshold IMT device was used. Furthermore, there were no significant differences in the primary outcome between protocols, which indicated that home-based training is non-inferior to a centerbased protocol.

The role of home-based respiratory rehabilitation has been highlighted in the era of the COVID-19 pandemic $[37,38]$. Exercise adherence--previously one of the barriers to home-based training--was greater than $90 \%$ in all groups in this study. Of course, the high adherence rate seen in those who completed the training may have been a result of some selection bias, but the adherence rates were comparable between protocols. In addition, patient withdrawal from home-based training groups was less than that of center-based training. This result suggested that the lack of information and motivation, one of the barriers to pulmonary rehabilitation, can be overcome by using a single supervised home-based RMT.

\section{Exercise performance}

Several studies have reported an improved effect of RMT on exercise performance in healthy individuals [39-41]. The protocol of alternating inspiratory and expiratory muscle training showed a better effect on exercise performance than a single type of RMT alone [11]. RMT also had a greater effect in less-fit participants, such as older individuals [27, 28]. Although we expected an improvement in exercise performance because of the population targeted, the mean value of the predicted $\mathrm{VO}_{2}$ peak showed no significant improvement. We considered that there were two reasons for this result. First, the RMT device used in this study had a low maximum threshold setting and thus could not be sufficiently raised with exercise intensity. Second, various tests, such as the incremental test, constant load test, and time trial, have been used in an attempt to assess the effect of RMT on exercise performance improvement, but significant improvement was confirmed only with the constant load and time trial test [11]. In this study, it was difficult to verify the effect of exercise tolerance because the incremental ramp protocol (the Chester step test) was selected to measure aerobic capacity due to the limitation of the research equipment.

\section{Diaphragm thickness and muscle mass}

Low muscle mass and age-related sarcopenia also affect respiratory muscle strength in older individuals, triggering vulnerability to disease and disability [6]. RMT strengthens and improves the thickness and movement of the diaphragm, which is the main inspiratory muscle [4]. In this study, significant improvements in diaphragm thickness were found in groups $\mathrm{N}-\mathrm{C}, \mathrm{N}-\mathrm{H}$, and $\mathrm{I}-\mathrm{H}$.

In BIA, the phase angle is presented as an alternative predictor of health in the aging process $[42,43]$. In this study, the initial phase angle exceeded the average value of $5.32 \pm 0.62$ in the community-dwelling older people that was previously reported [44]. In addition, the skeletal muscle index was higher than the $7.0 \mathrm{~kg} / \mathrm{m}^{2}$ presented by the Asian Working Group for Sarcopenia [3]. We observed no significant improvements in muscle mass or phase angle in any group. We assume that the initial 
values were markedly superior, such that the low intensity of RMT did not influence these results. In future, it will be necessary to evaluate these effects on frail older individuals or patients with respiratory diseases.

\section{Respiratory muscle activation during RMT}

Loaded breathing leads to greater activation of the neck muscles [45]. Generally, it is necessary to use accessory respiratory muscles and the diaphragm for effective RMT. Therefore, single-channel sEMG on the left SCM was used in the first and final training sessions to provide visual feedback of accessory muscle activity, as well as an outcome measure. We expected that if the diaphragm was strengthened, activation of the accessory muscles to overcome the same threshold loading would be relatively reduced. However, no significant differences between before and after training were identified in any of the groups. A study of chronic obstructive pulmonary disease (COPD) patients suggested that PEP training reduces the activity of the SCM muscles during respiration, which implies improved respiratory efficiency [46]. In the community-dwelling older individuals with normal lung function, it was difficult to confirm a significant difference in RMS because there was little use of accessory muscles during quiet breathing, and the function of the diaphragm was sufficient to overcome the threshold. However, it can be expected that the combined IMT/ PEP training will show a difference in SCM muscle activity in COPD patients.

\section{Limitations}

There were some limitations to this study. First, significant effects, such as increased activity or aerobic capacity, could not be identified due to the low maximum thresholds in the devices used. In our next study, we plan to verify the clinical impact of the IMT/PEP device on patients with chronic lung disease. In addition, due to the limitations of the protocol, there was no re-evaluation within the 8-week intervention. Therefore, we did not readjust the threshold during the training period. Consequently, we expect that the load gradually decreased below $40 \%$ of the MIP during training as the respiratory effort became stronger.

\section{Conclusion}

We observed that the IMT/PEP device was non-inferior to and yielded additional effects compared to the verified Threshold IMT. The reduced training time and improved usability, which is associated with exercise adherence, provided further advantages. Furthermore, our results indicated that, if preceded by proper education, a homebased RMT alone with the new IMT/PEP could provide a sufficient effect in older individuals. In addition, the results of this study suggest that the new RMT device can be used as an effective treatment strategy, even in patients with chronic lung diseases that require pulmonary rehabilitation.

\begin{abstract}
Abbreviations
BMI: Body mass index; COPD: Chronic obstructive pulmonary disease; $\mathrm{FEV}_{1}$ : Forced expiratory volume in the first second; FVC: Forced vital capacity; IMT: Inspiratory muscle training; IPAQ: International Physical Activity Questionnaire; MCID: Minimal clinically important significance; MEP: Maximal expiratory pressure; MIP: Maximum inspiratory pressure; PCF: Peak cough flow; PEP: Positive expiratory pressure; RMS: Root mean square; RMT: Respiratory muscle training; SEMG: Surface electromyography; SMI: Skeletal muscle index; $\mathrm{VO}_{2}$ peak: Peak oxygen uptake.
\end{abstract}

\section{Acknowledgments}

We thank all personnel for their contribution to the study.

\section{Authors' contributions}

SHK and SCH conceived and designed the trial. MJS designed the randomization procedure. JML and SHK collected data. SHK and YBS conceptualized the manuscript. SHK wrote the paper and MJS, SCH, and YBS revised it critically. All authors have read and approved the final version of the manuscript.

\section{Funding}

This research was supported by a grant of the Korea Health Technology R\&D Project through the Korea Health Industry Development Institute (KHIDI), funded by the Ministry of Health \& Welfare, Republic of Korea (grant number: HI17C2397)

\section{Availability of data and materials}

The datasets used and/or analyzed during the current study are available from the corresponding author on reasonable request.

\section{Declarations}

\section{Ethics approval and consent to participate}

All participants provided written informed consent. All procedures of the study were performed in accordance with the amended Declaration of Helsinki. Ethics approval was obtained from the Institutional Review Boards (IRBs) of Pusan National University Hospital (IRB No. 1903-028-076) and Pusan National University Yangsan Hospital (IRB No. 03-2019-006).

\section{Consent for publication}

Not applicable.

\section{Competing interests}

The authors declare that they have no competing interests.

\section{Author details}

'Department of Rehabilitation Medicine, Biomedical Research Institute, Pusan National University Hospital, Busan, Republic of Korea. ${ }^{2}$ Department of Rehabilitation Medicine, Biomedical Research Institute, Pusan National University Hospital and Pusan National University School of Medicine, Busan, Republic of Korea. ${ }^{3}$ Busan Center for infectious Disease Control and Prevention, Pusan National University Hospital, Busan, Republic of Korea. ${ }^{4}$ Department of Rehabilitation Medicine, Research Institute for Convergence of Biomedical Science and Technology, Pusan National University Yangsan Hospital, Yangsan, Republic of Korea. 
Received: 19 October 2021 Accepted: 7 February 2022

Published online: 24 February 2022

\section{References}

1. Lalley PM. The aging respiratory system--pulmonary structure, function and neural control. Respir Physiol Neurobiol. 2013;187:199-210.

2. Britto RR, Zampa CC, De Oliveira TA, Prado LF, Parreira VF. Effects of the aging process on respiratory function. Gerontology. 2009;55:505-10.

3. Chen LK, Woo J, Assantachai P, Auyeung TW, Chou MY, lijima K, et al. Asian working Group for Sarcopenia: 2019 consensus update on sarcopenia diagnosis and treatment. J Am Med Dir Assoc. 2020;21:300-7.

4. Ohara DG, Pegorari MS, Dos Santos NO, Silva CD, Monteiro RL, Matos $A P$, et al. Respiratory muscle strength as a discriminator of sarcopenia in community-dwelling elderly: a cross-sectional study. J Nutr Health Aging. 2018:22:952-8.

5. Aoyagi Y, Park H, Park S, Shephard RJ. Habitual physical activity and health-related quality of life in older adults: interactions between the amount and intensity of activity (the Nakanojo study). Qual Life Res. 2010;19:333-8.

6. Visser M, Schaap LA. Consequences of sarcopenia Clin Geriatric Med. 2011;27:387-99.

7. Summerhill EM, Angov N, Garber C, McCool FD. Respiratory muscle strength in the physically active elderly. Lung. 2007;185:315-20.

8. de Mello RGB, Dalla Corte RR, Gioscia J, Moriguchi EH. Effects of physical exercise programs on sarcopenia management, dynapenia, and physical performance in the elderly: a systematic review of randomized clinical trials. J Aging Res. 2019;2019:1959486.

9. Souza H, Rocha T, Pessoa M, Rattes C, Brandão D, Fregonezi G, et al. Effects of inspiratory muscle training in elderly women on respiratory muscle strength, diaphragm thickness and mobility. J Gerontol A Biol Sci Med Sci. 2014;69:1545-53.

10. Kim J, Davenport P, Sapienza C. Effect of expiratory muscle strength training on elderly cough function. Arch Gerontol Geriatr. 2009;48:361-6.

11. Illi SK, Held U, Frank I, Spengler CM. Effect of respiratory muscle training on exercise performance in healthy individuals. Sports Med. 2012;42:707-24

12. Troosters T, Gosselink R, Janssens W, Decramer MJ. Exercise training and pulmonary rehabilitation: new insights and remaining challenges. Eur Respir Rev. 2010;19:24-9.

13. Abdelbasset WK. Stay home: role of physical exercise training in elderly individuals' ability to face the Covid-19 infection. J Immunol Res. 2020;2020:8375096.

14. Torriani-Pasin C, dos Santos Palma GC, Makhoul MP, de Araujo AB, Lara ARF, da Silva TA, et al. Adherence rate, barriers to attend, safety, and overall experience of a remote physical exercise program during the COVID19 pandemic for individuals after stroke. Front Psychol. 2021;12:647883.

15. García Pérez de Sevilla G, Barceló Guido O, la Cruz D, de la Paz M, Fernández AB, Alejo LB, et al. Remotely supervised exercise during the COVID-19 pandemic versus in-person-supervised exercise in achieving long-term adherence to a healthy lifestyle. Int J Environ Res Public Health 2021:18:12198.

16. Holland AE, Cox NS, Houchen-Wolloff L, Rochester CL, Garvey C, ZuWallack $\mathrm{R}$, et al. Defining modern pulmonary rehabilitation. An official American Thoracic Society workshop report. Ann Am Thorac Soc. 2021;18:e12-29.

17. Mar PL, Nwazue V, Black BK, Biaggioni I, Diedrich A, Paranjape SY, et al. Valsalva maneuver in pulmonary arterial hypertension: susceptibility to syncope and autonomic dysfunction. Chest. 2016;149:1252-60.

18. Hajiro T, Nishimura K, Tsukino M, Ikeda A, Koyama H, Izumi T. Analysis of clinical methods used to evaluate dyspnea in patients with chronic obstructive pulmonary disease. Am J Resp Crit Care Med. 1998:158:1185-9.

19. Evans JA, Whitelaw WA. The assessment of maximal respiratory mouth pressures in adults. Respir Care. 2009;54:1348-59.

20. Oh JY, Yang YJ, Kim BS, Kang JH. Validity and reliability of Korean version of international physical activity questionnaire (IPAQ) short form. J Korean Acad Fam Med. 2007;28:532-41.
21. Miller A. Lung function testing: selection of reference values and interpretative strategies. Am Rev Respir Dis. 1992;146:1368-9.

22. Enright PL, Lebowitz MD, Cockroft DW. Physiologic measures: pulmonary function tests. Asthma outcome. Am J Respir Crit Care Med. 1994;149(2 Pt 2):S9-18 discussion S19-20.

23. Nici L, Donner C, Wouters E, Zuwallack R, Ambrosino N, Bourbeau $J$, et al. American Thoracic Society/European Respiratory Society statement on pulmonary rehabilitation. Am J Respir Crit Care Med. 2006;173:1390-413.

24. Lee SC, Kang SW, Kim MT, Kim YK, Chang WH, Im SH. Correlation between voluntary cough and laryngeal cough reflex flows in patients with traumatic brain injury. Arch Phys Med Rehabil. 2013;94:1580-3.

25. Choi JK, Paek D, Lee JO. Normal predictive values of spirometry in Korean population. Tuberc Respir Dis. 2005;58:230-42.

26. Ueki J, De Bruin PF, Pride NB. In vivo assessment of diaphragm contraction by ultrasound in normal subjects. Thorax. 1995;50:1157-61.

27. Sykes K, Roberts A. The Chester step test-a simple yet effective tool for the prediction of aerobic capacity. Physiotherapy. 2004;90:183-8.

28. Buckley JP, Sim J, Eston RG, Hession R, Fox R. Reliability and validity of measures taken during the Chester step test to predict aerobic power and to prescribe aerobic exercise. Br J Sports Med. 2004;38:197-205.

29. Jang MH, Ahn SJ, Lee JW, Rhee MH, Chae D, Kim J, et al. Validity and reliability of the newly developed surface electromyography device for measuring muscle activity during voluntary isometric contraction. Comput Math Methods Med. 2018;2018:4068493.

30. Criswell E. Cram's introduction to surface electromyography. Jones \& Bartlett Publishers. 2010.

31. Fukuda TY, Echeimberg JO, Pompeu JE, Lucarelli PRG. Root mean square value of the electromyographic signal in the isometric torque of the quadriceps, hamstrings and brachial biceps muscles in female subjects. J Appl Res. 2010;10:32-9.

32. Beaumont $M$, Forget $P$, Couturaud F, Reychler $G$. Effects of inspiratory muscle training in COPD patients: a systematic review and meta-analysis. Clin Respir J. 2018;12:2178-88.

33. Ahmadnezhad L, Yalfani A, Gholami BB. Inspiratory muscle training in rehabilitation of low back pain: a randomized controlled trial. J Sport Rehabil. 2020;29:1151-8.

34. Gholami-Borujeni B, Yalfani A, Ahmadnezhad L. Eight-week inspiratory muscle training alters electromyography activity of the ankle muscles during overhead and single-leg squats: a randomized controlled trial. J Appl Biomech. 2020;37:13-20.

35. Blackstock FC, ZuWallack R, Nici L, Lareau SC. Why don't our patients with chronic obstructive pulmonary disease listen to us? The enigma of nonadherence. Ann Am Thorac Soc. 2016;13:317-23.

36. Sørensen D, Svenningsen H. Adherence to home-based inspiratory muscle training in individuals with chronic obstructive pulmonary disease. Appl Nurs Res. 2018;43:75-9.

37. Prvu Bettger J, Resnik LJ. Telerehabilitation in the age of COVID19: an opportunity for learning health system research. Phys Ther. 2020;100:1913-6.

38. Jácome C, Marques A, Oliveira A, Rodrigues LV, Sanches I. Pulmonary telerehabilitation: an international call for action. Pulmonology. 2020;26:335-7.

39. Volianitis S, McConnell AK, Koutedakis Y, McNaughton L, Backx K, Jones DA. Inspiratory muscle training improves rowing performance. Med Sci Sports Exerc. 2001;33:803-9.

40. Lomax M, Grant I, Corbett J. Inspiratory muscle warm-up and inspiratory muscle training: separate and combined effects on intermittent running to exhaustion. J Sports Sci. 2011;29:563-9.

41. Enright SJ, Unnithan VB. Effect of inspiratory muscle training intensities on pulmonary function and work capacity in people who are healthy: a randomized controlled trial. Phys Ther. 2011;91:894-905.

42. Yamada Y, Buehring B, Krueger D, Anderson RM, Schoeller DA, Binkley N. Electrical properties assessed by bioelectrical impedance spectroscopy as biomarkers of age-related loss of skeletal muscle quantity and quality. $J$ Gerontol A Biol Sci Med Sci. 2017;72:1180-6.

43. Tanaka S, Ando K, Kobayashi K, Seki T, Hamada T, Machino M, et al. Low bioelectrical impedance phase angle is a significant risk factor for frailty. Biomed Res Int. 2019;2019:6283153. 
44. Uemura K, Doi T, Tsutsumimoto K, Nakakubo S, Kim MJ, Kurita S, et al. Predictivity of bioimpedance phase angle for incident disability in older adults. J Cachexia Sarcopenia Muscle. 2020;11:46-54.

45. Rodrigues A, Louvaris Z, Dacha S, Janssens W, Pitta F, Vogiatzis I, et al. Differences in respiratory muscle responses to hyperpnea or loaded breathing in COPD. Med Sci Sports Exerc. 2020;52:1126-34.

46. Cardoso DM, Fregonezi GA, Jost RT, Gass R, Alberton CL, Albuquerque IM, et al. Acute effects of expiratory positive airway pressure (EPAP) on different levels in ventilation and electrical activity of sternocleidomastoid and parasternal muscles in chronic obstructive pulmonary disease (COPD) patients: a randomized controlled trial. Braz J Phys Ther. 2016;20:525-34.

\section{Publisher's Note}

Springer Nature remains neutral with regard to jurisdictional claims in published maps and institutional affiliations.

- fast, convenient online submission

- thorough peer review by experienced researchers in your field

- rapid publication on acceptance

- support for research data, including large and complex data types

- gold Open Access which fosters wider collaboration and increased citations

- maximum visibility for your research: over $100 \mathrm{M}$ website views per year

At BMC, research is always in progress.

Learn more biomedcentral.com/submissions 